\title{
Correction to: Composition of the Cutaneous Bacterial Community in Japanese Amphibians: Effects of Captivity, Host Species, and Body Region
}

Joana Sabino-Pinto ${ }^{1} \cdot$ Molly C. Bletz ${ }^{1} \cdot$ Mohammed Mafizul Islam $^{2} \cdot$ Norio Shimizu $^{3} \cdot$ Sabin Bhuju ${ }^{4} \cdot$ Robert Geffers $^{4}$. Michael Jarek $^{4}$ - Atsushi Kurabayashi ${ }^{2} \cdot$ Miguel Vences $^{1}$

Published online: 28 January 2021

(C) Springer Science+Business Media, LLC, part of Springer Nature 2021

Correction to: Microbial Ecology. https://doi.org/10.1007/s00248-016-0797-6

The original article contained an error in the sequence of the primer 515F, where it says "cacggtcgkcggegccatt" it should say "gtgccagcmgccgeggtaa". The original version has been corrected.

The online version of the original article can be found at https://oi.org/ 10.1007/s00248-016-0797-6

Joana Sabino-Pinto

joanasabinopinto@gmail.com

1 Zoological Institute, Braunschweig University of Technology,

Braunschweig, Germany

2 Institute for Amphibian Biology, Graduate School of Science,

Hiroshima University, Higashi-Hiroshima, Japan

3 Hiroshima University Museums, Hiroshima University,

Higashi-Hiroshima, Japan

4 Department of Genome Analytics, Helmholtz Centre for Infection Research, Braunschweig, Germany 